\title{
Changes in Amino Acid Composition Associated with Tolerance to Partial Desiccation of Celery Somatic Embryos
}

\author{
Yehoshua Saranga, David Rhodes, and Jules Janick \\ Department of Horticulture, Purdue University, West Lafayette, IN 47907-1165
}

\begin{abstract}
Additional index words. Apium graveolens, synthetic seed, abscisic acid, proline
Abstract. Tolerance to partial desiccation and amino acid composition of celery (Apium graveolens L. cv. SB 12) somatic embryos were investigated under various culture durations and with exogenous application of $1 \mu \mathrm{M}$ ABA, proline, and/or $\gamma$-aminobutyrate (GABA). ABA consistently increased tolerance to partial desiccation and elevated proline and GABA content of embryos. The changes in tolerance to partial desiccation associated with changes in culture duration (optimum 9 to 10 days) correlated with embryo proline content. Exogenous proline increased embryo proline content and tolerance to partial desiccation. Exogenous GABA increased embryo GABA content and tolerance to partial desiccation only when applied in combination with proline. Chemical name used: abscisic acid (ABA).
\end{abstract}

Desiccated somatic embryos have been proposed as a potential analog of true seed (Gray and Purohit, 1991; Gray et al., 1987; Janick et al., 1989; Kitto and Janick, 1985a). A key factor for the production of such synthetic seed is the ability of somatic embryos to survive desiccation and convert into normal seedlings. Several factors have been reported to increase desiccation tolerance of somatic embryos. These include a slow desiccation rate (Gray et al., 1987; Kim and Janick, 1989), supplementation of embryo production medium (EPM) with ABA (Kitto and Janick, 1985b; Senaratna et al., 1990), proline (Rim and Janick, 1990, 1991) or high sucrose concentration, chilling, or high culture density (Kitto and Janick, 1985b). Little is known about the manner by which these treatments induce desiccation tolerance, and it may be that some, if not all, of these factors activate a single physiological mechanism. For example, medium supplementation with ABA, known to induce proline accumulation (LaRosa et al., 1987), and exogenous proline may both be inducing desiccation tolerance by elevating embryo proline content.

The objective of this study was to investigate the relationship between changes in tolerance to partial desiccation of somatic celery embryos and amino acid composition. Changes in tolerance were induced by altering culture duration and supplementation of medium with $\mathrm{ABA}$, proline, and/or GABA.

\section{Materials and Methods}

Somatic embryo production. Callus was induced from leaf explants (10 to $15 \mathrm{~mm}$ long) of in vitro-grown plantlets of 'SB 12' celery. Seven to nine explants were cultured per petri dish $(100 \times 15 \mathrm{~mm})$, each containing $25 \mathrm{ml}$ of callus induction medium consisting of MS basal medium (Murashige and Skoog, 1962) (salts plus vitamins) supplemented with $2.3 \mu \mathrm{M}(2,4-$ dichlorophenoxy)acetic acid (2,4-D), $2.3 \mu \mathrm{M}$ kinetin, casein hydrolysate at $0.5 \mathrm{~g} \cdot \mathrm{liter}^{-1}$, Gelrite at $3 \mathrm{~g} \cdot \mathrm{liter}^{-1}$, and sucrose

Received for publication 12 Aug. 1991. Accepted for publication 28 Oct. 1991. Journal paper no. 12,636 of the Purdue Univ. Agricultural Experiment Station. We thank A. Altman, Faculty of Agriculture, Hebrew Univ. of Jerusalem, for providing the plant material. We gratefully acknowledge the assistance of K.$\mathrm{H}$. Kim. The cost of publishing this paper was defrayed in part by the payment of page charges. Under postal regulations, this paper therefore must be hereby marked advertisement solely to indicate this fact. The cost of publishing this paper was defrayed in part by the payment of page charges. Under postal regulations, this paper therefore must be hereby marked advertisement solely to indicate this fact. at $30 \mathrm{~g} \cdot$ liter $^{-1}$ (Nadel et al., 1989), and adjusted to $\mathrm{pH} 5.8$ before autoclaving. The cultures were maintained under dim fluorescent light, $1 \mu \mathrm{mol} \cdot \mathrm{m}^{-2} \cdot \mathrm{s}^{-1}$ photosynthetically active radiation (PAR), with a 16-h photoperiod.

After 28 days, callus was transferred into liquid EPM consisting of MS basal medium supplemented with $30 \mathrm{~g}$ sucrose/ liter. Inoculation density was 3 to $4 \mathrm{~g} / 100 \mathrm{ml}$ medium in 500$\mathrm{ml}$ Erlenmeyer flasks. Cultures were placed on a gyratory shaker (100 rpm) under $50 \mu \mathrm{mol} \cdot \mathrm{m}^{-2} \cdot \mathrm{s}^{-1}$ PAR (16-h photoperiod) for 3 days (first phase of the embryo production cycle) and then filtered through a stainless steel sieve ( $1 \mathrm{~mm}$ pore size), producing 1 to $1.5 \mathrm{ml}$ (packed volume) of proembryo mixture per flask. Proembryos $(0.4 \mathrm{ml})$ were subcultured into $50 \mathrm{ml}$ of fresh EPM in 250-ml flasks for another 7 days (second phase of the embryo production cycle), unless indicated otherwise. Torpedoshaped embryos were collected and used for desiccation tests or amino acid determination.

Embryo desiccation and rehydration. Thirty embryos from each flask (considered as an experimental plot) were placed in $60 \times 15-\mathrm{mm}$ petri dishes (30 per dish) for desiccation. Excessive medium was removed with Pasteur pipet and filter paper, and the dishes covered with lids lined with 7-cm-diameter filter papaer (Whatman No. 1). Petri dishes were kept in a dark chamber maintained at $92 \%$ relative humidity $(\mathrm{RH})$ with saturated solution of potassium nitrate (Winston and Bates, 1960) at 25C for 48 or $72 \mathrm{~h}$. In a previous study (Kim and Janick, 1989), a similar procedure produced embryos with a water content of $63 \%$ or $34 \%$, respectively; therefore, the term partial desiccation is used.

Embryos were rehydrated with EPM and transferred onto filter paper bridges $(5.5 \mathrm{~cm}$ Whatman No. 1 crimped to form a table), placed in petri dishes $(60 \times 15 \mathrm{~mm})$, and moistened with $2 \mathrm{ml}$ of EPM. Embryo survival (visible growth) and conversion (both root and shoot development) were determined 10 days after rehydration and expressed as a percentage of the total embryos. Nondesiccated embryos consistently gave $95 \%$ to $100 \%$ conversion.

Experimental procedures. Tolerance to partial desiccation and amino acid composition were studied in five experiments with three types of treatments:

1) Effect of culture duration (Expt. A1 and A2). Torpedo-

Abbreviations: EPM, embryo production medium; GABA, $\gamma$-aminobutyrate; PAR, photosynthetically active radiation. 
Table 1. Effect of ABA (1 $\mu \mathrm{M})$ applied at various periods of culture on embryo survival after partial desiccation $(72 \mathrm{~h}, 92 \% \mathrm{RH})$.

\begin{tabular}{|c|c|c|c|c|c|c|}
\hline \multicolumn{3}{|c|}{ ABA concn $(\mu \mathrm{M})$} & \multirow{2}{*}{$\begin{array}{c}\text { Expt. B1 }{ }^{z} \\
\text { Survival } \\
(\%)\end{array}$} & \multicolumn{2}{|c|}{ Expt. B2 } & \multirow{2}{*}{$\begin{array}{c}\text { Mean } \\
\text { survival } \\
(\%) \\
\end{array}$} \\
\hline $4-6$ & $\begin{array}{c}\text { Days } \\
6-8 \\
\end{array}$ & $8-10$ & & $\begin{array}{c}\text { Survival } \\
(\%)\end{array}$ & $\begin{array}{c}\text { Conversion } \\
(\%)\end{array}$ & \\
\hline 0 & 0 & 0 & 0.0 & 5.7 & 2.3 & 2.9 \\
\hline 0 & 0 & 1 & 6.7 & 37.8 & 8.9 & 22.2 \\
\hline 0 & 1 & 0 & 0.8 & 0.0 & 0.0 & 0.4 \\
\hline 0 & 1 & 1 & 27.1 & 23.3 & 0.0 & 25.2 \\
\hline 1 & 0 & 0 & 2.5 & 15.4 & 0.0 & 8.9 \\
\hline 1 & 0 & 1 & 6.7 & 27.4 & 4.4 & 17.0 \\
\hline 1 & 1 & 0 & 4.9 & 30.0 & 0.0 & 17.5 \\
\hline 1 & 1 & 1 & 15.7 & 42.1 & 11.5 & 28.9 \\
\hline \multicolumn{7}{|c|}{ Main effects of days 4 to 6} \\
\hline 0 & & & 7.4 & 17.7 & 3.4 & 12.5 \\
\hline 1 & & & 7.5 & 28.5 & 4.8 & 18.0 \\
\hline \multicolumn{7}{|c|}{ Main effects of days 6 to 8} \\
\hline & 0 & & 4.0 & 21.6 & 3.9 & 12.8 \\
\hline & 1 & & 11.1 & 25.4 & 4.3 & 18.2 \\
\hline \multicolumn{7}{|c|}{ Main effects of days 8 to 10} \\
\hline & & 0 & 2.1 & 10.4 & 0.8 & 6.2 \\
\hline & & 1 & 13.2 & 33.5 & 6.8 & 23.3 \\
\hline & & & $* *$ & $* *$ & $*$ & \\
\hline
\end{tabular}

\footnotetext{
${ }^{* * * *}$ Conversion was not determined.
Significant main effect at $P=0.05$ or 0.01 , respectively.
}

shaped embryos were harvested after 8, 10, or 12 days in Expt. A1 and daily from 8 to 12 days in Expt. A2; this was accomplished by altering the length of the second phase of the embryo production cycle. Embryos were cultured with or without $1 \mu \mathrm{M}$ ABA added on day 3 (beginning of the second production phase). Treatments were replicated three times.

2) Effect of ABA application time (Expt. B1 and B2). Factorial experiments were performed, during which $1 \mu \mathrm{M}$ ABA was either applied or not, at all combinations of three periods, days 4 to 6,6 to 8 , and 8 to 10 (Table 1). Four of the eight treatments-without ABA (control) and with ABA applied on days 8 to 10,6 to 10 , or 4 to 10 -were analyzed for amino acid composition (Expt. B1). The experiments were replicated four times (Expt. B1) or three times (Expt. B2).

3) Effect of exogenous amino acids (Expt. C). Based on results of the experiments described above, the following treat-

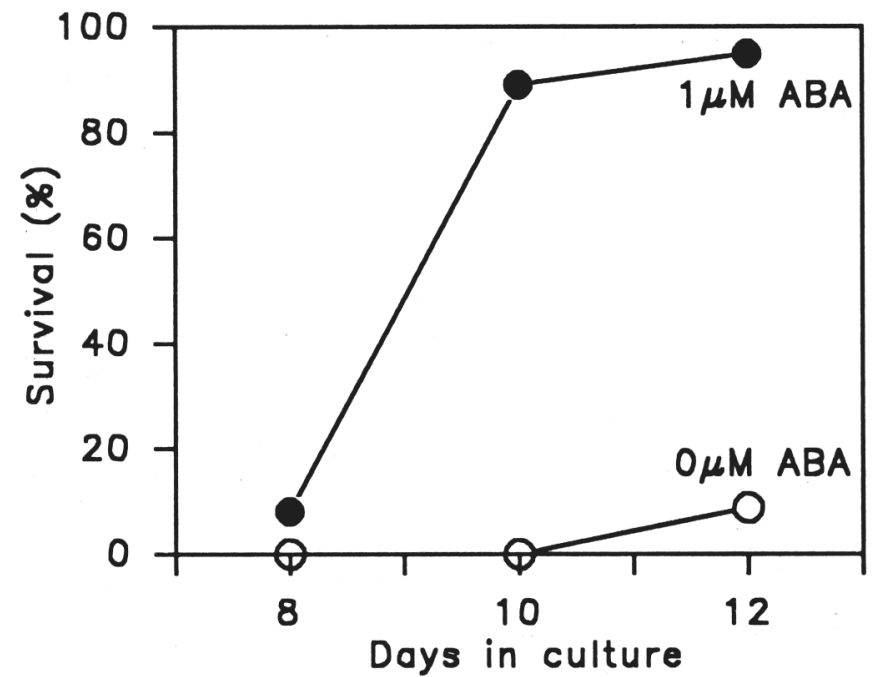

Fig. 1. Effect of culture duration and ABA on survival of celery somatic embryos after partial desiccation (48 h, 92\% RH), Expt. A1. ments, with or without $1 \mu \mathrm{M} \mathrm{ABA}$, were applied for the last 4 days of the 10-day production cycle: control, $1 \mu \mathrm{M}$ proline, $1 \mu \mathrm{M}$ GABA, $1 \mu \mathrm{M}$ proline $+1 \mu \mathrm{M}$ GABA. The experiment was performed with three replicates.

Amino acid determination. Amino acids were analyzed in three experiments (A2, B1, and C). Thirty torpedo-shaped embryos (50 to $70 \mathrm{mg}$ fresh weight) from each treatment and replication were washed with fresh EPM and weighed after removal of the excess medium. Amino acids were extracted with $1 \mathrm{ml}$ of methanol; $250 \mathrm{nmol}$ of L- $\alpha$-amino-n-butyrate was added as an internal standard. This compound was not detected in preliminary analyses of celery embryo amino acids lacking any added internal standard. Extracts were phase-separated by addition of $0.5 \mathrm{ml}$ chloroform and $0.6 \mathrm{ml} \mathrm{H}_{2} \mathrm{O}$. The upper aqueous layer was processed for amino acid analysis by ion-exchange chromatography (Dowex-50- $\mathrm{H}^{+}$) and gas-liquid chromatography as described by Brunk and Rhodes (1988), except that glutamate and glutamine, and aspartate and asparagine were not separated.

Data analysis. Analysis of variance was conducted using SAS software, general linear models procedure (Ray, 1982). Means were separated at $P=0.05$ by Student-Newman-Keuls' multiple range test.

\section{Results}

\section{Tolerance to partial desiccation}

Effect of culturing duration. In Expt. A1, survival of ABAtreated embryos increased from $8 \%$ on the 8 th day to $\approx 90 \%$ on days 10 and 12 (Fig. 1). Embryos cultured in hormone-free medium all died when harvested on days 8 and 10, whereas $9 \%$ survived on day 12. In Expt. A2, 95\% to $100 \%$ of ABA-treated embryos survived (Fig. 2a); their conversion increased from $40 \%$ on day 8 to $\approx 60 \%$ on days 9 through 12 (Fig. 2b). Survival and conversion of the embryos cultured in hormone-free me- 


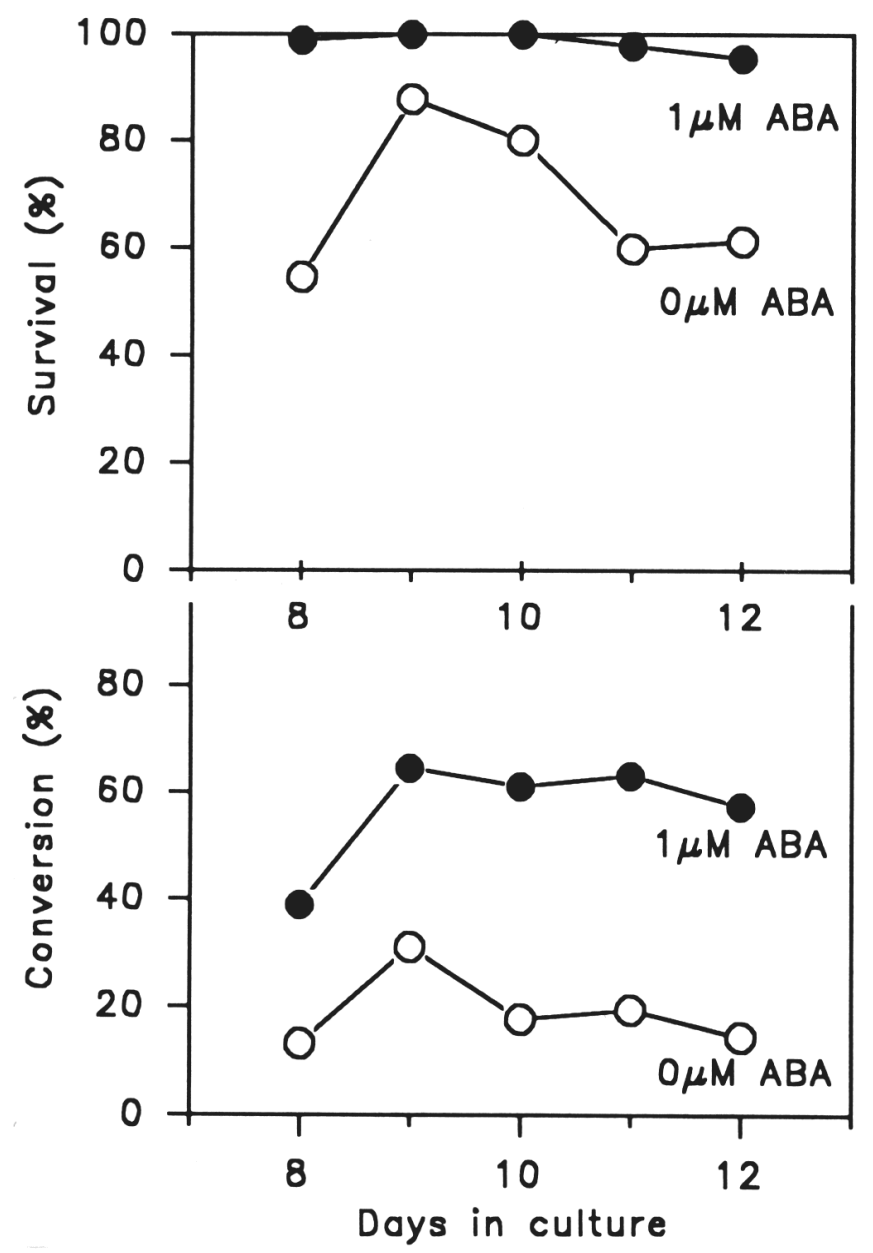

Fig. 2. Effect of culture duration and ABA on survival (a) and conversion (b) of celery somatic embryos after partial desiccation (48 h, 92\% RH), Expt. A2.

dium reached a maximum on day 9. In both experiments, tolerance to partial desiccation was increased (statistically significant) by ABA (Figs. 1 and 2).

Effect of ABA application time. In Expt. B1 and B2, where various intervals of ABA applications were examined, survival and conversion after partial desiccation were significantly increased by ABA applied for the last 2 days of the embryo production cycle (Table 1). Embryo survival after partial desiccation was nearly four times higher (mean of the two experiments) when ABA was applied for the last 2 days of the 10-day production cycle than when applied earlier. Analysis of main effects indicates that the promotive effect of $\mathrm{ABA}$ in increasing survivability is greatest at the end of the embryo production cycle, with some smaller effect from earlier application. Because a better synchronized culture (lower percentage of precocious germination) was observed with earlier ABA application, treatment was applied on day 4 in Expt. C.

Effects of exogenous amino acids. ABA also increased survival and conversion of somatic embryos in Expt. C (Table 2). Without ABA, proline and proline + GABA increased survival, but only the proline $+\mathrm{GABA}$ effect was significant at $P=$ 0.05. There was no evidence for an effect of GABA alone on survival. Survival of the amino acid-treated embryos did not differ from the control in the presence of ABA. A similar trend was found with conversion means: a small increase from GABA, a larger increase from proline, and the largest from the com-
Table 2. Effect of addition of $1 \mu \mathrm{M}$ ABA, exogenous proline, and/ or GABA (all $1 \mu \mathrm{M}$ ) on embryo survival after partial desiccation (48 h, 92\% RH). Significant interaction (amino acid x ABA) was found for survival and significant effects of $\mathrm{ABA}$ and amino acids in conversion; different letters indicate significant treatment differences $(P=0.05)$ between amino acids within columns ( $\mathrm{a}$ and $\mathrm{b})$ and ABA within rows ( $\mathrm{x}$ and $\mathrm{y}$ ) according to Student-NewmanKeuls' multiple range test.

\begin{tabular}{lccc}
\hline \hline & \multicolumn{3}{c}{ ABA treatment $(\mu \mathrm{M})$} \\
\cline { 2 - 4 } Amino acid added & 0 & 1 & Mean \\
\hline & $21.6 \mathrm{~b}$ & $75.7 \mathrm{a}$ & 48.6 \\
None & $\mathbf{y}$ & $\mathbf{X}$ & \\
& $52.2 \mathrm{~b}$ & $63.8 \mathrm{a}$ & 58.0 \\
Proline & $\mathbf{X}$ & $\mathbf{X}$ & \\
& $26.0 \mathrm{~b}$ & $62.4 \mathrm{a}$ & 44.2 \\
GABA & $\mathbf{x}$ & $\mathbf{X}$ & \\
& $86.8 \mathrm{a}$ & $77.5 \mathrm{a}$ & 81.2 \\
Proline + 1 GABA & $\mathbf{x}$ & $\mathbf{X}$ & \\
& 44.1 & 72.4 & \\
Mean & \multicolumn{4}{c}{ Conversion (\%) } \\
& 0.0 & 24.1 & $12.0 \mathrm{~b}$ \\
None & 7.4 & 43.5 & $25.5 \mathrm{ab}$ \\
Proline & 7.9 & 26.3 & $17.1 \mathrm{ab}$ \\
GABA & 22.9 & 34.3 & $29.8 \mathrm{a}$ \\
Proline + GABA & 8.9 & 32.4 & \\
Mean & $\mathbf{y}$ & $\mathbf{x}$ & \\
& &
\end{tabular}

bination of proline + GABA.

\section{Amino acids and tolerance to partial desiccation}

At least 17 amino acids were detected in celery somatic embryos, of which alanine and glutamate plus glutamine were the most abundant (Table 3). Endogenous concentrations of aspartate plus asparagine, proline, and threonine of embryos from Expt. A2 correlated significantly with survival and/or conversion of embryos grown in hormone-free medium (Fig. 3). Such correlations were not found with ABA treatments, probably due to the small variation in survival and conversion within the ABA treatment.

Amino acid concentration changes induced by ABA usually were similar in Expt. A2 and B1 (Table 3). In Expt. B1, the effect of ABA when applied on days 8 to 10 or 6 to 10 (not shown) was similar to the effect of application on days 4 to 10 . Although the concentration of most amino acids was reduced by ABA (nine of 17 in Expt. A2 and 11 of 17 in Expt. B1), the most striking changes were the increase of GABA and proline levels found in Expt. B1 and to a lesser extent in Expt. A2.

Amino acid concentrations in Expt. $\mathrm{C}$ were in the same range as previously observed and were similarly affected by ABA (data not presented). GABA concentration in the embryo failed to increase when exogenous GABA was applied alone, but increased when GABA and proline were applied together (Table 4). Application of proline alone or proline + GABA increased embryo proline content 6-fold in the absence of ABA, and 3fold in the presence of ABA. There was no evidence of substantial changes in other amino acids induced by proline and/or GABA (not shown).

\section{Discussion}

Increases in tolerance to partial desiccation of somatic embryos with time in culture were somewhat inconsistent, but max- 
Table 3. Amino acid content of celery somatic embryos without (control) or with ABA $(1 \mu \mathrm{M})$. Each datum is a mean of 15 samples harvested on days 8 to 12 (Expt. A2) or three samples harvested on day 10 (Expt. B1).

\begin{tabular}{|c|c|c|c|c|c|c|}
\hline \multirow[b]{4}{*}{$\begin{array}{l}\text { Amino } \\
\text { acid }\end{array}$} & \multicolumn{3}{|c|}{ Expt. A2 } & \multicolumn{3}{|c|}{ Expt. B1 } \\
\hline & \multicolumn{6}{|c|}{$\overline{\text { Amino acid content }}$} \\
\hline & \multirow{2}{*}{$\begin{array}{c}\text { Control } \\
\left(\mu \mathrm{mol} \cdot \mathrm{g}^{-1}\right. \\
\text { fresh wt })\end{array}$} & \multicolumn{2}{|c|}{$\begin{array}{c}+\mathrm{ABA} \\
\text { day } 3\end{array}$} & \multirow{2}{*}{$\begin{array}{c}\text { Control } \\
\left(\mu \mathrm{mol} \cdot \mathrm{g}^{-1}\right. \\
\text { fresh } \mathrm{wt})\end{array}$} & \multicolumn{2}{|c|}{$\begin{array}{c}+\mathrm{ABA} \\
\text { day } 4\end{array}$} \\
\hline & & $\begin{array}{l}\left(\mu \mathrm{mol} \cdot \mathrm{g}^{-1}\right. \\
\text { fresh wt })\end{array}$ & $\begin{array}{c}(\% \text { of } \\
\text { control }) \\
\end{array}$ & & $\begin{array}{l}\left(\mu \mathrm{mol} \cdot \mathrm{g}^{-1}\right. \\
\text { fresh wt })\end{array}$ & $\begin{array}{c}\text { (\% of } \\
\text { control) }\end{array}$ \\
\hline$\overline{\text { Ala }}$ & 16.32 & 11.04 & $68 * * *$ & 9.01 & 9.59 & 106 \\
\hline GABA & 1.63 & 1.94 & $119^{* *}$ & 0.65 & 1.98 & $306^{*}$ \\
\hline Arg & 0.28 & 0.20 & 72 & 0.39 & 0.28 & 73 \\
\hline Asp + Asn & 4.25 & 5.20 & $122 * * *$ & 3.70 & 3.29 & 89 \\
\hline Cys & 0.05 & 0.06 & 105 & 0.10 & 0.11 & 106 \\
\hline Glu + Gln & 67.65 & 53.38 & $79 * * *$ & 74.85 & 47.43 & $63^{*}$ \\
\hline Gly & 0.46 & 0.24 & $51 * * *$ & 0.66 & 0.31 & 46 \\
\hline His & 1.24 & 1.19 & 96 & 1.24 & 0.57 & 46 \\
\hline Ileu & 0.28 & 0.25 & 91 & 0.26 & 0.19 & 75 \\
\hline Leu & 0.67 & 0.60 & $90^{*}$ & 0.60 & 0.52 & 87 \\
\hline Orn & 0.48 & 0.53 & 111 & 0.95 & 0.50 & 53 \\
\hline Phe & 0.15 & 0.18 & $126^{* * *}$ & 0.13 & 0.14 & 106 \\
\hline Pro & 2.61 & 3.26 & $125^{* *}$ & 1.68 & 4.35 & $259 * * *$ \\
\hline Ser & 3.40 & 2.77 & $81 * * *$ & 2.43 & 2.11 & 87 \\
\hline Thre & 1.60 & 1.41 & $88 * * *$ & 1.40 & 1.12 & 80 \\
\hline Tyr & 0.31 & 0.33 & 106 & 0.27 & 0.30 & 112 \\
\hline Val & 2.84 & 2.27 & $80 * * *$ & 2.37 & 1.96 & 83 \\
\hline Total & 104.22 & 84.85 & $81 * * *$ & 102.69 & 74.75 & $74 *$ \\
\hline
\end{tabular}

imum survival was obtained in both experiments after nine to 10 culturing days (Figs. 1 and 2). This result suggests that important metabolic changes occurred in embryos during this morphological stage.

The increased tolerance to partial desiccation induced by ABA was consistent in all five experiments (Figs. 1 and 2, Table 1) and confirms previous studies with celery (Kim and Janick, 1989), carrot (Daucus carota L.) (Kitto and Janick, 1985b), and alfalfa (Medicago sativa L.), for which application at the late embryo production phase was critical (Senaratna et al., 1990). Our results show clearly that embryos were the most receptive to induction of desiccation tolerance by $\mathrm{ABA}$ in the last 2 days of culturing (Table 1). This feature indicates that the effect of ABA is relatively rapid (2 days or less).

The increased tolerance to partial desiccation achieved with proline in Expt. C (Table 2) confirms previous results of Kim and Janick (1990). Application of proline together with ABA increased conversion, indicating complementation between these compounds.

Proline, aspartate plus asparagine, and threonine levels were positively correlated with desiccation tolerance in the absence of ABA in Expt. A2 (Fig. 3). If these amino acids contribute to desiccation tolerance, their concentration could be expected to increase in response to $\mathrm{ABA}$ application. $\mathrm{ABA}$ treatment increased proline in both Expt. A2 and B1, and increased aspartate plus asparagine in Expt. A2 (Table 3). The increased concentrations of proline and GABA were accompanied by a reduction of glutamate plus glutamine, where glutamate is the precursor of proline and GABA (Rhodes et al., 1986).

Proline content of somatic embryos increased greatly in response to exogenous proline application (Table 4); about a 20$\mu \mathrm{mol} \cdot \mathrm{g}^{-1}$ fresh weight increase was achieved from the addition of $1 \mu \mathrm{mol}$ praline/ml of medium. This increase suggests active absorption of proline by embryos.
Table 4. Effect of the addition of ABA and exogenous proline and/ or GABA (all $1 \mu \mathrm{M}$ ) on the specific content of these compounds in celery somatic embryos. Mean separation by Student-Newman-KenIs' multiple range test, $P=0.05$.

\begin{tabular}{lcr}
\hline \hline \multirow{2}{*}{$\begin{array}{l}\text { Amino acid } \\
\text { added }\end{array}$} & \multicolumn{1}{c}{ Content $\left(\mu \mathrm{mol} \cdot \mathrm{g}^{-1}\right.$ fresh wt) } \\
\cline { 2 - 3 } & GABA & Proline \\
\hline \multirow{3}{*}{$\begin{array}{l}\text { None } \\
\text { Proline }\end{array}$} & Main effect of amino acid application \\
GABA & $4.41 \mathrm{~b}$ & $6.03 \mathrm{~b}$ \\
Proline + GABA & $4.68 \mathrm{~b}$ & $27.03 \mathrm{a}$ \\
& $4.42 \mathrm{~b}$ & $4.00 \mathrm{~b}$ \\
None & $5.47 \mathrm{a}$ & \\
ABA & Main effect of ABA application & \\
\hline
\end{tabular}

Our results indicate that elevated proline content in the embryo, achieved by either altering culture duration or by application of exogenous ABA or proline, can enhance tolerance to partial desiccation. Proline was proposed as a desiccation protectant (Stewart and Hanson, 1980), and it accumulates in response to osmotic stress (Rhodes et al., 1986) and ABA application (LaRosa et al., 1987). GABA may have some additional effects on tolerance to partial desiccation that require further investigation. It may be significant that both proline and GABA synthesis rates increase in water-stress-adapted cell cultures of tomato (Lycopersicon esculentum Mill.) (Rhodes et al., 1986). Application of ABA with proline further improved tolerance to partial desiccation relative to proline alone, without any noticeable changes in amino acid composition. ABA has been reported to increase the levels of other metabolites in somatic embryos, such as fatty acids in celery (Kim and Janick, 1990, 1991) and starch in alfalfa (Fujii et al., 1989). This effect 


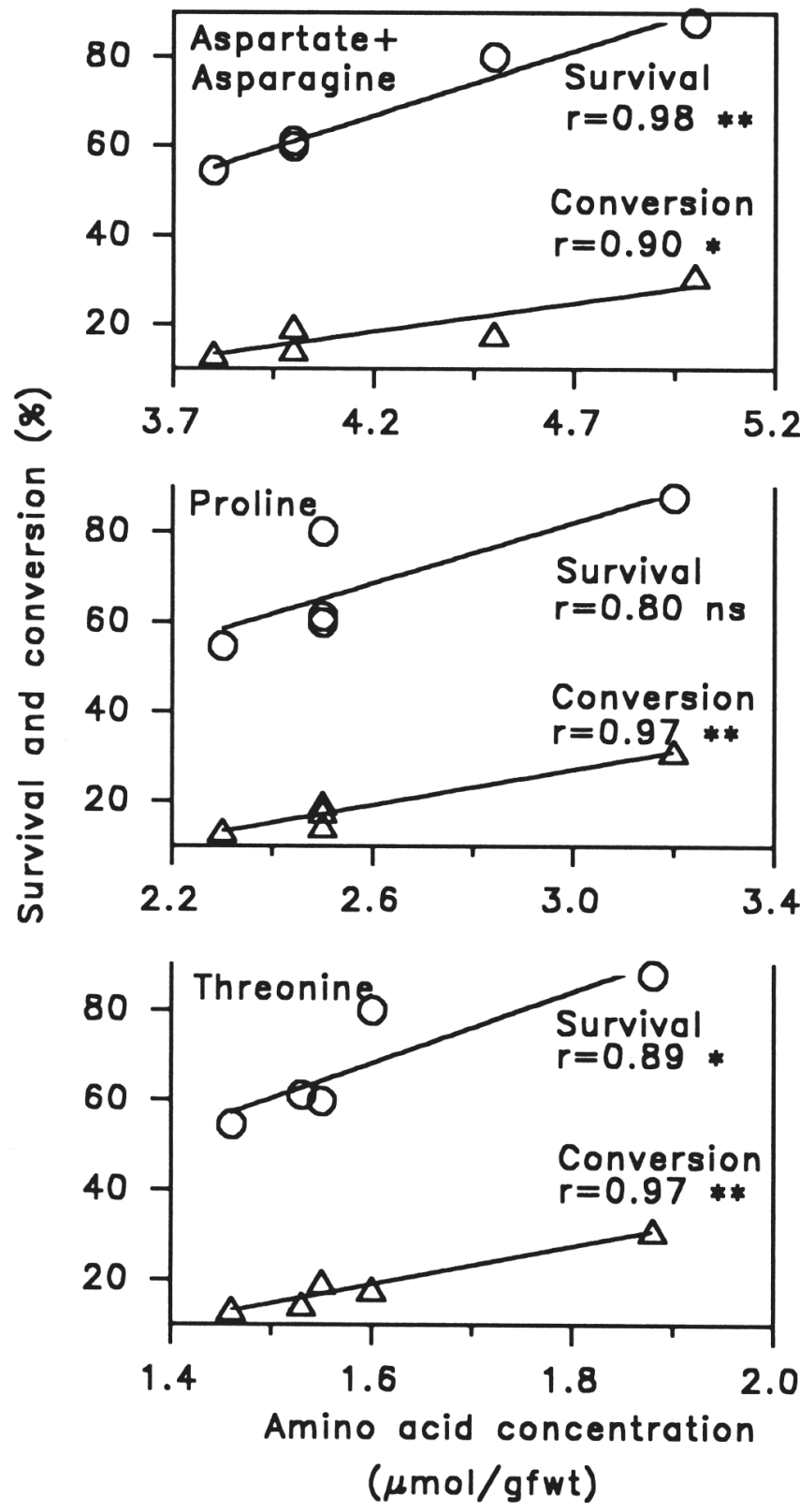

Fig. 3. Correlations between amino acid contents and survival and conversion of celery somatic embryos after partial desiccation (48 h, 92\% RH), Expt. A2. Each point is a mean of three replicates at each harvest date. $* * * *$ Significant correlation coefficient at $P=0.05$ or 0.01 , respectively. suggests that ABA has a multifaceted influence in inducing tolerance to partial desiccation; increasing proline concentration appears to play an important role in this process.

\section{Literature Cited}

Brunk, D.G. and D. Rhodes. 1988. Amino acid metabolism of Lemna minor L. III. Responses to aminooxyacetate. Plant Physiol. 87:447453.

Fujii, J.A., D. Slade, R. Olsen, S.E. Ruzin, and K. Redenbaugh. 1989. ABA maturation and starch accumulation in alfalfa somatic embryos. In Vitro Cell Dev. Biol. 25:61A. (Abstr.)

Gray, D.J., B.V. Conger, and D.D. Songstad. 1987. Desiccated quiescent somatic embryos of orchardgrass for use as synthetic seeds. In Vitro 23:29-33.

Gray, D.J. and A. Purohit. 1991. Somatic embryogenesis and development of synthetic seed technology. Critical Rev. Plant Sci. 10:3361.

Janick, J., S.L. Kitto, and Y-H. Kim. 1989. Production of synthetic seed by desiccation and encapsulation. In Vitro Cell Dev. Biol. 25:1167-1174.

Kim, Y-H. and J. Janick. 1989. ABA and polyox-encapsulation or high humidity increases survival of desiccated somatic embryos of celery. HortScience 24:674-676.

Kim, Y-H. and J. Janick. 1990. Synthetic seed technology: Improving desiccation tolerance of somatic embryos of celery. Acta Hort. 280:2328.

Kim, Y-H. and J. Janick. 1991. Abscisic acid and proline improve desiccation tolerance and increase fatty acid content of celery somatic embryos. Plant Cell Tissue Organ Cult. 24:83-89.

Kitto, S.L. and J. Janick. 1985a. Production of synthetic seeds by encapsulating asexual embryos of carrot. J. Amer. Soc. Hort. Sci. 110:277-282.

Kitto, S.L. and J. Janick. 1985b. Hardening treatment increased survival of synthetically-coated asexual embryos of carrot. J. Amer. Soc. Hort. Sci. 110:283-286.

LaRosa, P.C., P.M. Hasegawa, D. Rhodes, J.M. Clithero, A-E. A. Watad, and R.A. Bressan. 1987. Abscisic acid stimulated osmotic adjustment and its involvement in adaptation of tobacco cells to NaCl. Plant Physiol. 85:174-181.

Murashige, T. and F. Skoog. 1962. A revised medium for rapid growth and bioassays with tobacco tissue cultures. Physiol. Plant. 15:473497.

Nadel, B.L., A. Altman, and M. Ziv. 1989. Regulation of somatic embryogenesis in celery cell suspensions. 1. Promoting effects of mannitol on somatic embryo development. Plant Cell Tissue Organ Cult. 18:181-189.

Ray, A.A. (ed.). 1982. SAS user's guide: Statistics. SAS Institute, Cary, N.C. p. 584.

Rhodes, D., S. Handa, and R.A. Bressan. 1986. Metabolic changes associated with adaptation of plant cells to water stress. Plant Physiol. 82:890-903.

Senaratna, T., B.D. McKersie, and S.R. Bowley. 1990. Artificial seeds of alfalfa (Medicago sativa L.). Induction of desiccation tolerance in somatic embryos. In Vitro Cell Dev. Biol. 26:85-90.

Stewart, C.R. and A.D. Hanson. 1980. Proline accumulation as a metabolic response to water stress, p. 173-189. In: N.C. Turner and P.J. Kramer (eds.). Adaptation of plants to water and high temperature stress. Wiley, New York.

Winston, P.W. and D.H. Bates. 1960. Saturated solutions for the control of humidity in biological research. Ecology 41:232-237. 